\title{
EFEITOS DA DENERVAÇÃO EM MUSCULO SOLEUS DE RATOS
}

\author{
J. A. KOUYOUMDJIAN * \\ O. MARCATO ** \\ L. A. MARQUES **
}

O efeito da denervação em músculos em geral é conhecido, principalmente em experimentos com mamíferos. São conhecidas as alterações nucleares, as alterações no calibre das fibras musculares, a percentagem de perda de peso, a preservação das estriações e as alterações de tecido conjuntivo que sofre o músculo após denervação. Esses achados característicos foram descritos no trabalho clássico de Adams e revisões de outros autores 1,2.

O objetivo do presente estudo é o de repetir esse clássico experimento e observarmos essas anormalidades dando ênfase às alterações histológicas e às alterações tróficas. Realizamos tal trabalho em nosso meio, servindo de estímulo aos que se iniciam no estudo de patologia muscular.

\section{MATERIAL E METODOS}

O experimento foi realizado em 38 ratos Wistar do sexo feminino com peso variando de 164 a 290 gramas. O músculo testado foi sempre o músculo soleus esquerdo, servindo o direito como controle. A diferença normal de peso entre o músculo soleus direito e o esquerdo foi estabelecida em 10 ratos normais.

O nervo ciático esquerdo foi seccionado em 28 animais, retirando-se um fragmento de aproximadamente $5 \mathrm{~mm}$, evitando-se assim a regeneração do nervo pela proximidade dos dois cotos, proximal e distal. Os músculos soleus direito e esquerdo foram retirados após $3,5,7,10,12,17,21,30,40$ e 50 días após a denervação. Imediatamente após a retirada dos músculos, estes foram pesados e a curva de perda estabelecida. Fotografias macrescópicas foram obtidas em tempos varíaveis. Em seguida o material foi encaminhado ao laboratório de histologła, fixado em formol $10 \%$ e preparado em parafina segundo técnicas convencionais. Os cortes histológicos transversais e longitudinais foram feitos com espessura de $10_{\mu}$ e preparados para coloração em hematoxilina-eosina. Fotografias microscópicas foram feitas das lâminas, usando-se fotomicroscópio Zeiss com objetivas números 16 e 40.

Faculdade de Medicina de São José do Rio Preto, SP: *Chefe da Disciplina de Neurologia; * Doutorandos. 


\section{RESULTADOS}

A. Peso - A diferença normal de peso em miligramos fol estabelecida entre os músculos soleus esquerdo e direito em 10 ratos normais. $O$ músculo soleus direito serviu sempre como controle e os valores negativo ou positivo dados ao músculo soleus esquerdo são relativos a ele. A tabela 1 mostra os resultados obtidos, evidenciando-se uma baixa variabilidade de peso entre os dois lados, pois a média da percentagem da diferença foi de $(+) \quad 0,61$.

Os resultados obtidos no peso dos músculos após denervação em períodos variados de tempo (3o até $50^{\circ}$ dia) são mostrados na tabela 2 . Observa-se já no $3^{\circ}$ dia após denervação uma diminuição de peso porém não significativa. Essa diminuição se acentuou quando foi alcançado o $10^{\circ}$ dia, observando-se $18,3 \%$ de atrofia já macroscopicamente visível. Por volta do $20^{\circ}$ dia foi observado hipotrofia de todo membro posterior denervado e uma diminuição de peso de aproximadamente $45 \%$ em comparação com o lado controle. A atrofia continuou se acentuando, atingindo aproximadamente $54 \%$ no $30^{\circ}$ dia. Nas aferições subsequientes $\left(40^{\circ}\right.$ e $50^{\circ}$ dias), todo o membro mostrava-se muito mais atrofiado e o músculo soleus assemelhava-se a um cordão no lado denervado.

Comparando os resultados obtidos em relação às percentagens de atrofia, pudemos observar que nas primeiras três semanas (até 210 dia) houve $45 \%$ de perda muscular e subsequentemente (22\% até $50 \%$ dia) apenas $17 \%$. A evolucão da atrofia muscular é mostrada no gráfico 1 .

B. Alteraçōes histológicas - $\mathrm{O}$ aspecto histológico do músculo soleus (HE) evidencia basicamente fibras poligonais regulares de mesmo calibre, núcleos periféricos picnóticos e alongados, fusos musculares esparsos e as estriações características nos cortes longitudiriais. Esses apectos são mostrados nas figuras 1 e 2.

\begin{tabular}{|c|c|c|c|c|c|c|}
\hline & & $\begin{array}{c}\text { Direito } \\
\text { Controle }\end{array}$ & $\begin{array}{l}\text { Esquerdo } \\
\text { Teste }\end{array}$ & Diferen & & $\%$ \\
\hline \multirow[t]{10}{*}{ Soleus } & 1 & 167 & 174 & $(+)$ & 7 & 4,19 \\
\hline & 2 & 164 & 167 & (t) & 3 & 1,82 \\
\hline & $\mathbf{3}$ & 139 & 136 & (一) & 3 & 2,15 \\
\hline & 4 & 136 & 134 & (一) & 2 & 1,47 \\
\hline & 5 & 103 & 105 & (+) & 2 & 1,94 \\
\hline & 6 & 118 & 130 & (t) & 12 & 10,16 \\
\hline & 7 & 93 & 96 & (t) & 3 & 3,22 \\
\hline & 8 & 115 & 106 & $(\rightarrow)$ & 9 & 7,82 \\
\hline & 9 & 110 & 114 & $(+)$ & 4 & 3,63 \\
\hline & 10 & 136 & 126 & $(-)$ & 10 & 7,35 \\
\hline \multirow{2}{*}{\multicolumn{2}{|c|}{$\begin{array}{l}\text { Média } \\
\text { Desvio } \\
\text { Padrão }\end{array}$}} & 1 & 1 & $(+)$ & 0,70 & $(+) 0,61$ \\
\hline & & I & I & & 6,83 & 5,47 \\
\hline
\end{tabular}

Tabela 1 - Comparacão entre os pesos (mg) dos músculos soleus direito e esquerdo em ratos normais. $O$ sinal (t) ou (-) é dado em relagáo ao musculo soleus direito (controle). 


\begin{tabular}{|c|c|c|c|c|c|}
\hline Dia & No de & e Ratos & $\begin{array}{c}\text { Soleus D. } \\
\text { Controle }\end{array}$ & $\begin{array}{l}\text { Soleus } \mathbf{E .} \\
\text { Teste }\end{array}$ & M\% \\
\hline \multirow[t]{3}{*}{$3^{\circ}$} & & 3 & 135 & 125 & $-2,8$ \\
\hline & & & 111 & 116 & \\
\hline & & & 127 & 120 & \\
\hline \multirow[t]{2}{*}{$5^{\circ}$} & & 2 & 130 & 118 & $-8,9$ \\
\hline & & & 171 & 156 & \\
\hline \multirow[t]{3}{*}{70} & & 3 & 142 & 125 & $-11,2$ \\
\hline & & & 119 & 100 & \\
\hline & & & 149 & 140 & \\
\hline \multirow[t]{3}{*}{$10^{\circ}$} & & 3 & 200 & 161 & $-18,3$ \\
\hline & & & 161 & 129 & \\
\hline & & & 201 & 166 & \\
\hline \multirow[t]{3}{*}{12} & & 3 & 155 & 112 & $-25,8$ \\
\hline & & & 155 & 119 & \\
\hline & & & 132 & 97 & \\
\hline \multirow[t]{3}{*}{$17^{\circ}$} & & 3 & 200 & 127 & $-33,7$ \\
\hline & & & 200 & 130 & \\
\hline & & & 118 & 83 & \\
\hline \multirow[t]{3}{*}{$21^{\circ}$} & & 3 & 134 & 71 & $-44,8$ \\
\hline & & & 112 & 69 & \\
\hline & & & 138 & 70 & \\
\hline \multirow[t]{3}{*}{$30^{\circ}$} & & 3 & 130 & 53 & $-53,4$ \\
\hline & & & 141 & 82 & \\
\hline & & & 135 & 57 & \\
\hline \multirow[t]{3}{*}{$400^{\circ}$} & & 3 & 112 & 50 & $-54,9$ \\
\hline & & & 132 & 60 & \\
\hline & & & 122 & 55 & \\
\hline \multirow[t]{2}{*}{$50^{\circ}$} & & 2 & 165 & 59 & $-61,8$ \\
\hline & & & 200 & 81 & \\
\hline
\end{tabular}

\footnotetext{
As alterações histológicas observadas foram nítidas e podem ser assim delineadas: os núcleos sarcolemais assumiram aspecto oval e/ou arredondado com nucléolos proeminentes; houve evidente aumento no número de núcleos, apesar de não ter sido feita a contagem dos mesmos; houve diminuição de calibre das fibras musculares; não houve anormalidades nas estriaçöes ou no tecido conjuntivo. Todas estas anormalidades foram notadas já na 1ạ semana e no final do 10 mês estavam marcantes. Os núcleos sarcolemais apresentavam-se mais dilatados e vesiculares, alguns com aspecto tigróide; persistia o aumento numérico dos mesmos. A redução no calibre das fibras musculares foi se acentuando e estas perderam sua forma poligonal característica e assumiram forma
} 


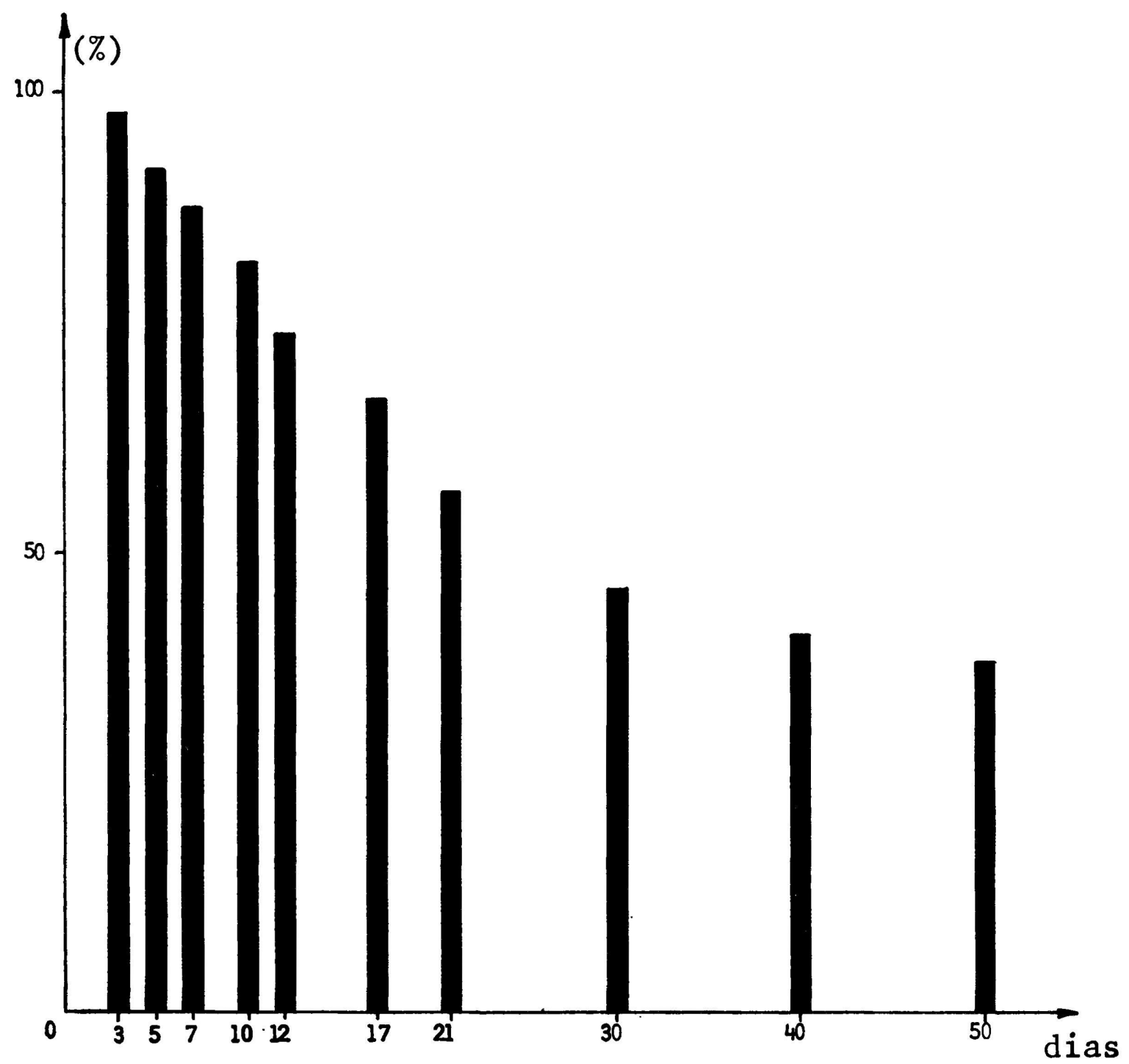

Gráfico 1 - Evolucão da percentagem de queda de peso (atrofia) em músculos soleus de ratos pos-denervacão.
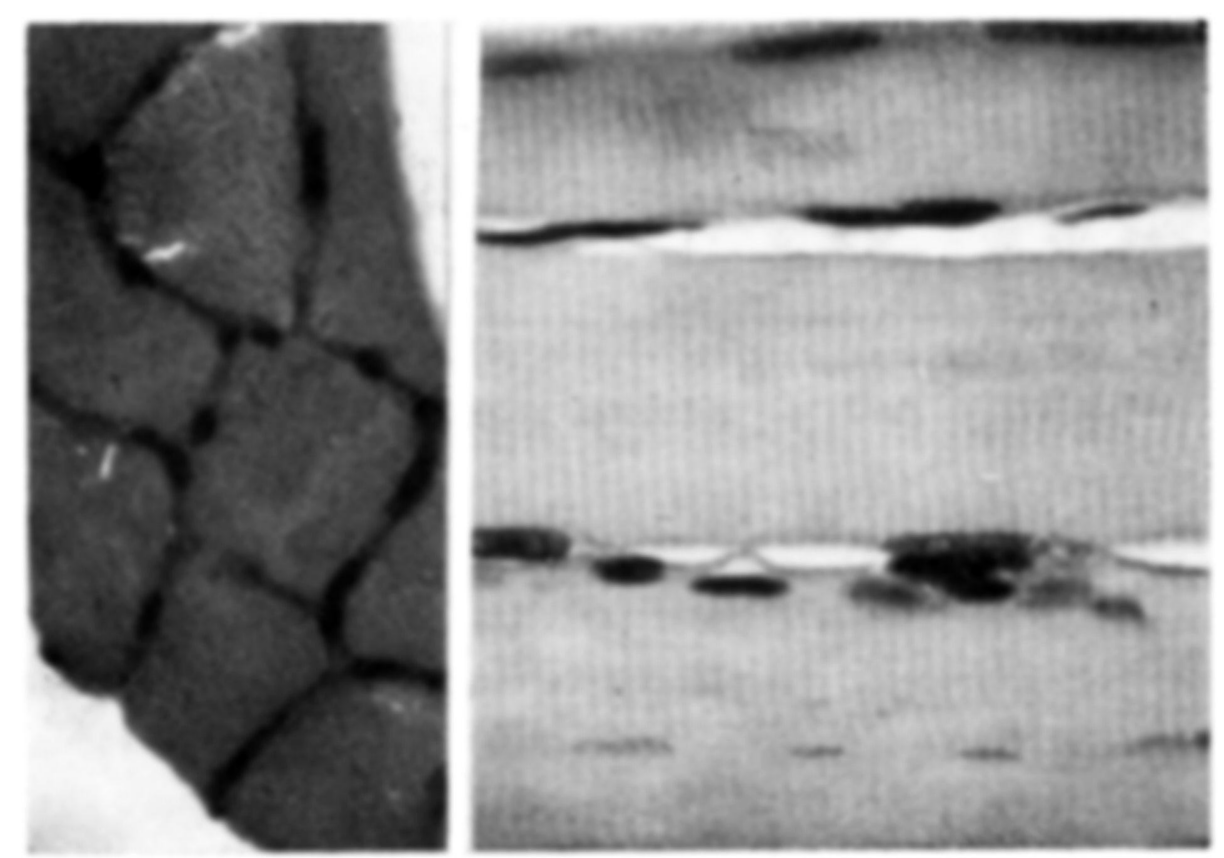

Figuras 1 e 2 - Aspecto microscópico (HE) do músculo soleus normal. Figura 1: corte transversal x40. Erigura 2: corte longitudinal $\times 40$. 
arredondada. Nas fases mais adiantadas do experimento observou-se discreta proliferação conjuntiva endomisial em algumas áreas. As estriações permaneceram inalteradas por todo o experimento. As anormalidades histológicas são mostradas nas figuras 3, 4, $5,6,7$ e 8 .

A tabela 3 sumariza todas as alterações observadas no trabalho, mostrando a percentagem de atrofia, alterações macroscópicas no músculo e no membro e as alterações histológicas.
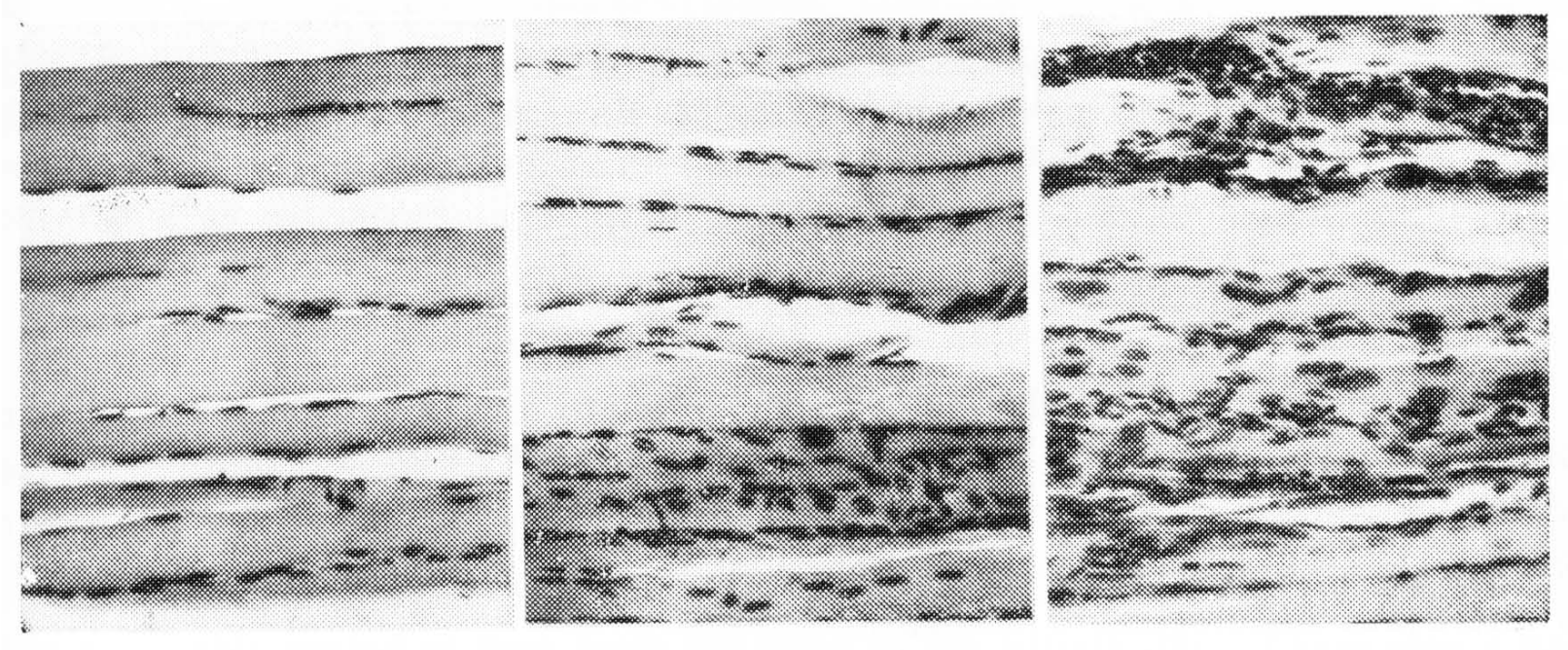

Figuras 3, 4 e 5 - Aspecto microscópuco (HE) em corte longitudinal do músculo soleus x16. Fignura 3: normal. Figura 4: 7 dias após denervação. Figura 5: 30 dias após denervação.
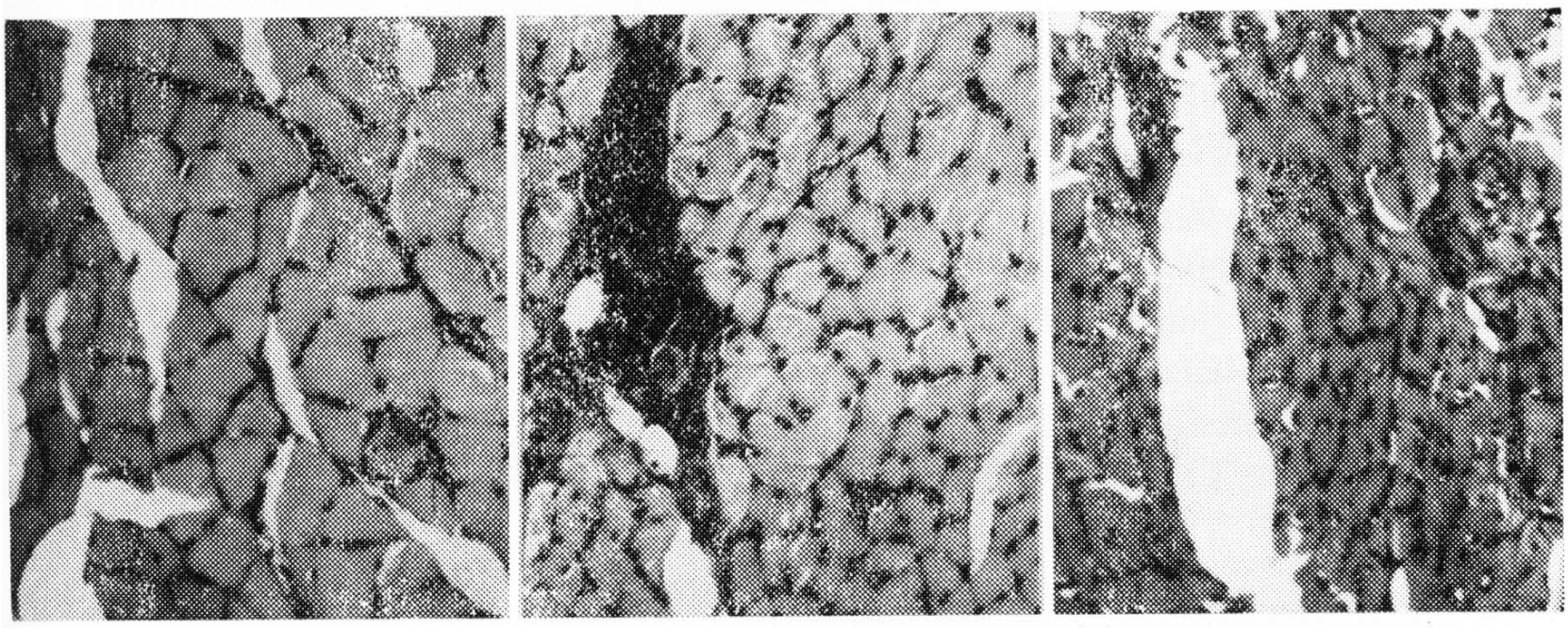

Figuras 6, 7 a 8 - Aspecto microscópico (HE) em corte transversal do músculo soleus x16. Figura 6: 3 dias após denervação. Figura $7: 30$ dias após denervação. Figura 8: 50 dias após denervação. 


\begin{tabular}{|c|c|c|c|c|c|c|c|c|}
\hline & & Alts. de peso & $\begin{array}{l}\text { Evidên } \\
\text { macros } \\
\text { de atro }\end{array}$ & & $\begin{array}{c}\text { Altera- } \\
\text { cões } \\
\text { de }\end{array}$ & $\begin{array}{c}\text { Altera- } \\
\text { cões } \\
\text { no }\end{array}$ & $\begin{array}{c}\text { Altera- } \\
\text { cões } \\
\text { das }\end{array}$ & $\begin{array}{c}\text { Altera- } \\
\text { cões } \\
\text { no }\end{array}$ \\
\hline & & $\%$ de atrofia & $\begin{array}{l}\text { Musc. } \\
\text { soleus }\end{array}$ & $\begin{array}{c}\text { Membro } \\
\text { inf. }\end{array}$ & núcleo & $\begin{array}{c}\text { da } \\
\text { fibra }\end{array}$ & estrias & $\begin{array}{l}\text { tec. } \\
\text { conj. }\end{array}$ \\
\hline & 39 dia & $3 \%$ & - & 一 & + & 一 & - & - \\
\hline $7^{9}$ & $-100 \mathrm{~d}$ & $18 \%$ & + & - & +++ & - & - & - \\
\hline & $20^{\circ} \mathrm{d}$ & $45 \%$ & $+t$ & - & $++t$ & + & - & - \\
\hline & $300 \mathrm{~d}$ & $53 \%$ & ++ & + & $++t$ & ++ & - & + \\
\hline & $500 \mathrm{~d}$ & $61 \%$ & $+t+$ & ++ & +++ & $t+t$ & - & + \\
\hline
\end{tabular}

Tabela 3 - Sumário das alteracóes observadas pós-denervacão: (+) discreto, (+十) moderado e $(+++)$ evidente.

\section{COMENTARIOS}

As alterações observadas mostraram o efeito da denervação em músculo soleus de ratos. Notamos basicamente as mesmas alterações observadas por Adams ${ }^{1}$ e Astrom e Adams (citados por Walton 2). As transformações ocorridas no músculo após denervação foram analisadas detalhadamente com ênfase às alterações histológicas e tróficas.

O decréscimo de peso foi bastante acentuado nos primeiros 30 dias e observamos cerca de $50 \%$ de atrofia muscular nesse período: A seguir, até n $50 \%$ dia o decréscimo foi menor, atingindo cerca de $15 \%$. Essas anormalidades são idênticas às encontradas na literatura e mostram atrofia precoce e em seguida um plateau na curva atrófica.

As alterações nos núcleos sarcolemais foram importantes e precoces, sendo já observadas no 3o dia após denervação. Eles se tornaram volumosos, arredondados ou ovalados e com nucléolos proeminentes, diferindo acentuadamente dos núcleos sarcolemais normais. Por volta do 79 dia estas alterações foram máximas e houve um aparente aumento no número de núcless, sendo este aumento ainda questionado por alguns autores, segundo Adams ${ }^{1 .}$

As alterações verificadas no diâmetro das fibras musculares não corresponderam à diminuição de peso verificada nas primeiras semanas. Assim sendo, houve discreta redução no calibre das fibras musculares nas duas primeiras semanas e acentuada redução após 50 dias. As fibras musculares progressivamente foram mudando de forma, tornando-se arredondadas. Houve discreta irregularidade no padrão de atrofia, sendo esta algo maior ou menor nos diferentes fascículos.

Coincidentemente com a literatura não notamos alterações acentuadas no tecido conjuntivo nas primeiras semanas. Foi observada discreta proliferação do tecido conjuntivo endomisial a partir do $30^{\circ}$ dia. Como nos demais experimentos não encontramos alterações nas estriações em nenhuma fase do músculo 
denervado, indicando integridade nas miofibrilas com provável diminuição apenas numérica.

\section{RESUMO}

As alteraç̃es histológicas e a evolução de peso foram estudadas em músculo soleus de ratos após denervação do nervo ciático. Os músculos foram retirados em períodos de tempo que variaram de 3 a 50 dias. Houve redução progressiva de peso com cerca de $50 \%$ de atrofia na 3 semana, atingindo-se um plateau ao redor do $50 \mathrm{o}$ dia. As anormalidades histológicas mais acentuadas ocorreram nos núcleos, que se tornaram vesiculares, com nucléolos proeminentes e com aparente aumento de número; tais anormalidades foram observadas já na primeira semana. Houve redução de cerca de $50 \%$ no calibre das fibras musculares que se tornaram arredondadas. As normalidades de tecido conjuntivo foram discretas e as estriações persistiram inalteradas por todo tempo do estudo.

\section{SUMMARY}

\section{Dennervation effects on rat soleus muscle.}

Histological aspects and changes in wet weight were studied on rat soleus muscles after dennervation by cutting the sciatic nerve. The muscles were removed after a variable period of time from the third to the fiftieth day. There was a progressive fall off in wet weight and after the third week the muscles underwent $50 \%$ atrophy. Histological changes were most striking on sarcolemmal nuclei; they became vesicular, enlarged with prominent nucleolus and there was an apparent increase in their number. The muscle fibres changed their shape, becoming rounded and there was a $50 \%$ reduction in muscle fibre diameter after 50 days. Connective tissue abnormalities were minimal after 50 days and the striations remained intact.

\section{REFERENCIAS}

1. ADAMS, R. D. - Diseases of Muscle: A Study in Pathology. Part II: Pathologic Reactions of Skeletal Muscle. Chapter 3: Experimental Pathology. Harper \& Row Publishers Inc., Hagerstown. Third Edition, 1975.

2. WALTON, J. B. - Disorders of Voluntary Muscle. Chapter 5: Pathological Reactions of the Skeletal Muscle Fibre in Man. Churchill Livingstone, Edinburgh - London - Melbourne - New York, Fourth Edition, 1981.

Frundação Fraculdade de Medicina de são José do Rio Preto - Departamento de Medicina Integrada, Disciplina de Neurologia - Av. Fraria Lima 5544 - 15100 São Jose do Rio Preto, SP - Brasil. 